\title{
Reduced Flavin: NMR investigation of N(5)-H exchange mechanism, estimation of ionisation constants and assessment of properties as biological catalyst
}

Peter Macheroux ${ }^{1}$, Sandro Ghisla*2, Christoph Sanner ${ }^{3}$, Heinz Rüterjans ${ }^{3}$ and Franz Müller ${ }^{4}$

Address: ${ }^{1} \mathrm{Graz}$ University of Technology, Institute of Biochemistry, Petersgasse 12, A-8010 Graz, Austria, ${ }^{2}$ Fachbereich Biologie, Universität Konstanz, D-78457 Konstanz, Germany, ${ }^{3}$ Institut fur Biophysikalische Chemie, J.W. Goethe-Universität, Biozentrum N230, Marie-Curie-Strasse 9, D-60439 Frankfurt am Main, Germany and ${ }^{4}$ Wylstrasse 13, CH-6052 Hergiswil, Switzerland

Email: Peter Macheroux - peter.macheroux@tugraz.at; Sandro Ghisla* - sandro.ghisla@uni-konstanz.de; Christoph Sanner - hruet@bpc.unifrankfurt.de; Heinz Rüterjans - hruet@bpc.uni-frankfurt.de; Franz Müller - franzmueller@bluewin.ch

* Corresponding author

Published: 25 November 2005

BMC Biochemistry 2005, 6:26 doi:10.1 I86/147I-209I-6-26
Received: 27 June 2005

Accepted: 25 November 2005

This article is available from: http://www.biomedcentral.com/I47I-209I/6/26

(C) 2005 Macheroux et al; licensee BioMed Central Ltd.

This is an Open Access article distributed under the terms of the Creative Commons Attribution License (http://creativecommons.org/licenses/by/2.0), which permits unrestricted use, distribution, and reproduction in any medium, provided the original work is properly cited.

\begin{abstract}
Background: The flavin in its FMN and FAD forms is a versatile cofactor that is involved in catalysis of most disparate types of biological reactions. These include redox reactions such as dehydrogenations, activation of dioxygen, electron transfer, bioluminescence, blue light reception, photobiochemistry (as in photolyases), redox signaling etc. Recently, hitherto unrecognized types of biological reactions have been uncovered that do not involve redox shuffles, and might involve the reduced form of the flavin as a catalyst. The present work addresses properties of reduced flavin relevant in this context.

Results: $\mathrm{N}(5)-\mathrm{H}$ exchange reactions of the flavin reduced form and its $\mathrm{pH}$ dependence were studied using the ${ }^{15} \mathrm{~N}-\mathrm{NMR}$-signals of ${ }^{15} \mathrm{~N}$-enriched, reduced flavin in the $\mathrm{pH}$ range from 5 to 12 . The chemical shifts of the $N(3)$ and $N(5)$ resonances are not affected to a relevant extent in this $\mathrm{pH}$ range. This contrasts with the multiplicity of the $\mathrm{N}(5)$-resonance, which strongly depends on $\mathrm{pH}$. It is a doublet between $\mathrm{pH} 8.45$ and $\mathrm{I} 0.25$ that coalesces into a singlet at lower and higher $\mathrm{pH}$ values. From the line width of the ${ }^{15} \mathrm{~N}(5)$ signal the $\mathrm{pH}$-dependent rate of hydrogen exchange was deduced. The multiplicity of the ${ }^{15} \mathrm{~N}(5)$ signal and the proton exchange rates are little dependent on the buffer system used.

Conclusion: The exchange rates allow an estimation of the $\mathrm{pK}_{\mathrm{a}}$ value of $\mathrm{N}(5)-\mathrm{H}$ deprotonation in reduced flavin to be $\geq 20$. This value imposes specific constraints for mechanisms of flavoprotein catalysis based on this process. On the other hand the $\mathrm{pK} \approx 4$ for $\mathrm{N}(5)-\mathrm{H}$ protonation (to form $\left.\mathrm{N}(5)^{+}-\mathrm{H}_{2}\right)$ would be consistent with a role of $\mathrm{N}(5)-\mathrm{H}$ as a base.
\end{abstract}

\section{Background}

The isoalloxazine ring system is the redox active moiety of the coenzyme forms (FMN or FAD) present in flavoen- zymes. These are involved in a variety of biological processes, spanning a wide spectrum with regard to the underlying chemical reaction mechanisms. These range 
from the classical (de)hydrogenation, the uptake, release and transport of electrons, the production of light (bioluminescence), photochemistry of the reduced form (as in photolyases), light signal transduction (as in blue light receptors), activation of oxygen and redox sensing, to name only the most prominent ones [1]. In addition to these functions, others have emerged that appear to require hitherto unrecognized roles of reduced flavin in chemical catalysis, such as reactions that are redox-neutral (for a review see [2]). These will be addressed briefly below.

In reduced flavin, N(5) is crucial for the functioning of the isoalloxazine system as it is the locus involved in uptake/ release of redox equivalents and is in general in contact with reacting ligands. In the intermediate $\mathrm{pH}$ range reduced flavin $\mathrm{N}(5)$ exists in its neutral, $\mathrm{N}(5)-\mathrm{H}$ form, it can be protonated to yield $\mathrm{N}(5) \mathrm{H}_{2}{ }^{+}$at low $\mathrm{pH}$ and might exist in the anionic form N(5)- at very high pH (cf Fig. 5, below). Based on kinetic arguments [3] Bruice and coworkers have estimated the $\mathrm{pK}_{\mathrm{a}}$ for deprotonation of this group as being around 20 in free flavin. Urban and Lederer, on the other hand, imply a value around 15 for flavocytochrome $\mathrm{b}_{2}[4]$ and it has been postulated that this $\mathrm{pK}$ might even be lower than 7 [5]. A method useful for the assessment of the properties of reduced flavin, and specifically of N(5) is the nuclear magnetic resonance (NMR) spectroscopy. It has been used to study the interactions of apoprotein and flavin, and the perturbations of these interactions induced by binding of substrate/ligands[6]. In these studies, we have observed that the $\mathrm{N}(5) \mathrm{H}$ group in most two-electron reduced flavoproteins appears as a doublet in the ${ }^{15} \mathrm{~N}-\mathrm{NMR}$ spectrum due to the $\mathrm{N}(5)$-H coupling, while free flavin exhibits a singlet in the $\mathrm{pH}$ range 5-8 due to fast proton exchange. Therefore, the doublets observed in reduced flavoproteins have been interpreted as resulting from the absence or from slow proton exchange on the NMR time scale. This can result from inaccessibility of the $\mathrm{N}(5) \mathrm{H}$ group to bulk water. However, no systematic study on the basic mode of N(5)-H exchange in free reduced flavin in aqueous solution is available. The great variety of chemical reactions mentioned above raises the question about the physical interactions between the apoprotein and the coenzyme that are responsible for the tuning necessary to catalyze particular reactions.

A detailed knowledge of this process and of its mechanism would provide several insights into flavoenzyme structure and function: a) It would provide a basis for the interpretation of ${ }^{15} \mathrm{~N}-\mathrm{NMR}$ spectra of reduced flavoproteins. b) It could help understand a variety of exchange processes of substrate/product-linked hydrogens in various dehydrogenation reactions involving flavoproteins. c) It might help clarify the possible role of reduced flavin in the $\beta$ - elimination of halide from $\beta$-halogenated substrates catalyzed by several flavoproteins. X-ray structural information has shown that there are no basic amino acid residues at the active centers of e.g. (oxidized) D-amino acid oxidase [7-9]. The hypothesis has thus been put forward that $\mathrm{N}(5)$ of the reduced enzyme flavin is the base that is involved in enzyme catalyzed elimination [10]. In addition labeled hydrogen is abstracted from the $\alpha$ position and is partially incorporated into the $\beta$ position of product [11]. These data would also be compatible with the proposed role of reduced flavin N(5)-H being involved in label transposition/exchange $[7-9,12]$. d) Chorismate synthase catalyzes a redox-neutral anti-1,4-elimination of a hydrogen and a phosphate group and has an absolute requirement for a reduced FMN cofactor. Again, it has been assumed that an amino acid functional group serves as a base in the elimination of the hydrogen but the recent elucidation of the 3D-structure has revealed that the only functional group that could be invoked in this process is the $N(5)$ position of the flavin $[12,13]$. e) Based on recent studies it has been proposed that in the dehydrogenation reaction catalyzed by monoamine oxidase, the flavin N(5) of the postulated $\mathrm{C}(4 \mathrm{a})$-flavin substrate adduct (which is isoelectronic with the flavin hydroquinone) acts as a base in hydrogen abstraction [14]. Thus, a critical functional role of the flavin N(5) nitrogen in its reduced 1,5-dihydro, or its isoelectronic 4a,5-dihydro forms appears to emerge. The present study was undertaken to increase our understanding of processes involving this position and specifically the pH-dependent proton exchange and to gain information on the basicity/nucleophilicity of $\mathrm{N}(5)$ in reduced flavin, which provides basic information on possible mechanistic roles in flavoenzyme catalysis.

\section{Results and Discussion Chemical shifts}

The $\mathrm{pH}$-dependence of the ${ }^{15} \mathrm{~N}$ chemical shifts of reduced free flavin (N(1), N(3), N(5), N(10)) has been previously investigated at $\mathrm{pH} 5.2-8$ [15], a pH range where most flavoproteins are active and stable. This study revealed that the chemical shift of the $\mathrm{N}(1)$ atom in reduced free flavin is strongly $\mathrm{pH}$-dependent due to its ionization. $\mathrm{A} \mathrm{pK}_{\mathrm{a}}$ value of 6.8 was calculated for this process [15]. Also the signal of the $\mathrm{N}(10)$ atom shows a similar $\mathrm{pH}$-dependence; the chemical shift difference between that of the neutral and of the anionic species, however, is smaller than that of the N(1) atom. This observation was rationalized previously as resulting from a change of $\mathrm{sp}^{2}$ hybridization of the $N(10)$ atom $[15,16]$. The chemical shifts of the $N(3)$ and the $\mathrm{N}(5)$ atom are practically independent of $\mathrm{pH}$ in the range studied. In aqueous solution only a singlet was observed for the $\mathrm{N}(5) \mathrm{H}$ and the $\mathrm{N}(3) \mathrm{H}$ groups. The signal of the $\mathrm{N}(3) \mathrm{H}$ group remains as a sharp, narrow line over the $\mathrm{pH}$ range studied, whereas that of the $\mathrm{N}(5) \mathrm{H}$ group 

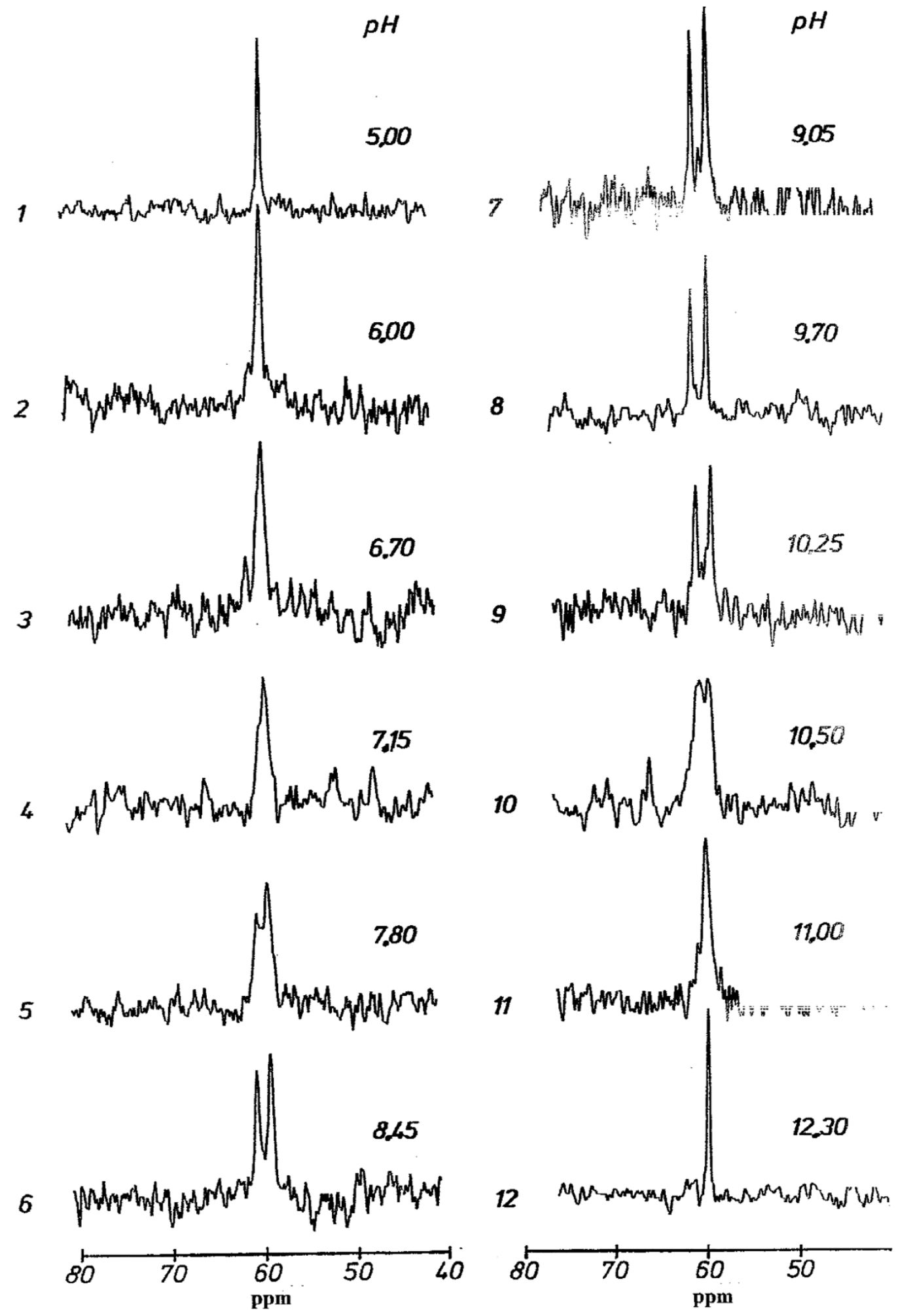

Figure I

Multiplicity of the ${ }^{15} \mathbf{N}-\mathbf{N M R}$ signal of the reduced FMN N(5)H group as a function of $\mathrm{pH}$. The flavin concentration was $5 \mathrm{mM}$ in $250 \mathrm{mM}$ Tris + $100 \mathrm{mM} \mathrm{NaCl}$. The obtained FID was processed further by exponential multiplication using a line broadening factor of $20 \mathrm{~Hz}$ in order to improve the signal to noise ratio. 
exhibits a sharp line at $\mathrm{pH} 5.4$ and a broadened one at $\mathrm{pH}$ 7 and higher $[15,16]$.

In the present study the $\mathrm{pH}$-dependence of the ${ }^{15} \mathrm{~N}$ chemical shifts of reduced free flavin was extended to the $\mathrm{pH}$ range 4.0 to 12.3 . The ${ }^{15} \mathrm{~N}$ chemical shifts at $\mathrm{pH} 4.0$ are identical, or almost identical to those observed earlier at pH $5.0[15,16]$, with the exception that the chemical shift of the $\mathrm{N}(1)$ atom is shifted upfield by $1.4 \mathrm{ppm}$. Also at $\mathrm{pH}$ 12.3 the ${ }^{15} \mathrm{~N}$ chemical shifts of the $\mathrm{N}(5)$ and $\mathrm{N}(10)$ atoms are identical with those reported previously for $\mathrm{pH} 8.0$ $[15,16]$. The ${ }^{15} \mathrm{~N}$ chemical shift of the $\mathrm{N}(3)$ atom shows a slight downfield shift $(+1.9 \mathrm{ppm})$ at $\mathrm{pH}>11$ indicating the onset of deprotonation of the $\mathrm{N}(3) \mathrm{H}$ group. Also a small downfield shift $(+0.7 \mathrm{ppm})$ is observed for the $\mathrm{N}(1)$ atom in the high $\mathrm{pH}$ region, probably related to the (partial) ionization of the $\mathrm{N}(3) \mathrm{H}$ group.

\section{Signal structure of the $N(5)-H$ resonance}

The two nitrogen atoms in reduced free flavin bearing a hydrogen are $\mathrm{N}(3)$ and $\mathrm{N}(5)$. The signal of $\mathrm{N}(3)$ appears as a singlet in the $\mathrm{pH}$ range studied and from this rapid exchange can be assumed. As shown in Fig. 1 the shape of the $\mathrm{N}(5)$ resonance signal depends strongly on the $\mathrm{pH}$. At low $\mathrm{pH}$ values there is a sharp singlet that broadens with increasing $\mathrm{pH}$. Above $\mathrm{pH} 7.15$ the broad singlet begins to show a doublet structure (first coalescence point), the resolution of which increases and finally gives rise to a doublet ( $\mathrm{pH} 8.45-10.25$ ). Further increase of the $\mathrm{pH}$ leads to broadening of the doublet lines again and eventually to a second coalescence point around pH 10.5 (see also below). At even higher $\mathrm{pH}$ values the signal becomes again a sharp singlet. These data demonstrate that below the first and above the second coalescence point we have two $\mathrm{pH}$ regions of fast hydrogen exchange. This is supported by the fact that the line widths of the decoupled and undecoupled resonance lines are identical $(4 \mathrm{~Hz}$, natural line width) at $\mathrm{pH} 12.3$ and $\mathrm{pH}$ 5.0. In the $\mathrm{pH}$ range between the two coalescence points the exchange is comparatively slow. The asymmetric shape of the doublet (higher intensity of the high field line in Fig. 1, pH 8.45 $10.25)$ can be a result of either the high magnetic field (11.4 Tesla), which causes a prevailing contribution of the CSA-relaxation mechanism [17] or could be due to a particular proton exchange mechanism [18]. Which of the two effects is prevailing, cannot be deduced from the present data.

The ${ }^{1} \mathrm{~J}^{15} \mathrm{~N}(5)-\mathrm{H}$ coupling constant can be determined from the spectra obtained in the slow exchange region (Fig. 1, spectra 7 and 8) and was found to be $85 \mathrm{~Hz}$. This value agrees well with that determined previously in a $\mathrm{CHCl}_{3}$ solution $(87.5 \mathrm{~Hz})$ [15]. The coupling constant of reduced flavin is similar to those reported for eneamines and aniline derivatives [19]. ${ }^{1}{ }^{15} \mathrm{~N}-\mathrm{H}$ coupling constants are mainly governed by the hybridization of the nitrogen atom. A low s-character gives rise to small coupling constant (the coupling constant for tetrahedral ammonia is $73 \mathrm{~Hz}$ ) whereas a high s-character results in a high coupling constant (for linear nitriles coupling constants as high as $135 \mathrm{~Hz}$ have been found [20]). The observed coupling constant of $85 \mathrm{~Hz}$, which is similar to the value found for pyrrole $(96.5 \mathrm{~Hz}[20])$, indicates that the N(5) atom possesses approximately $31 \%$ s-character, i.e. it is highly $\mathrm{sp}^{2}$ hybridized. The $\mathrm{pH}$-dependence of the shape of the N(5)-resonance was not affected by buffer systems like Tris, phosphate and borate.

\section{Determination of $\mathrm{N}(5)$-Hydrogen exchange rates}

The exchange rate of the N(5) hydrogen was determined using equation (1) for fast exchange (below $\mathrm{pH} 7.8$ and above $\mathrm{pH}$ 10.5) [21] and equation (2) for slow exchange (between pH 7.8 and 10.5) [22]:

$$
\begin{aligned}
& \mathrm{k}=1 / \tau_{\mathrm{e}}=4 \pi \mathrm{pA} \mathrm{pB} \Delta \mathrm{v}^{2} /\left(\Delta \mathrm{v}_{1 / 2}-\Delta \mathrm{v}_{1 / 2}{ }^{\circ}\right) \\
& \mathrm{k}=1 / \tau_{\mathrm{e}}=\pi\left(\Delta \mathrm{v}_{1 / 2}-\Delta v_{1 / 2}{ }^{\circ}\right)
\end{aligned}
$$

with $\mathrm{k}$ as the exchange rate; $\tau_{\mathrm{e}}$ the lifetime of each state, $\Delta v_{1 / 2}$ the half line width of the resonance line, $\Delta v_{1 / 2}{ }^{\circ}$ the half line width of the proton decoupled signal which should be equal to the so-called natural line width $(4 \mathrm{~Hz}$, see above) under conditions of fast proton exchange. $\Delta v$ is the difference of the resonance frequencies of the exchanging species under the condition of slow exchange, i.e. equal to the coupling constant ${ }^{1} \mathrm{~J}_{\mathrm{N}-\mathrm{H}^{\prime}} \mathrm{pA}$ and $\mathrm{pB}$ are the molar fractions of the exchanging species in state $\mathrm{A}$ and $\mathrm{B}$, respectively. The exchange rates have also been determined in phosphate and borate buffers at a few selected $\mathrm{pH}$ values; they are in the range of those determined in Tris buffer. The signal structure at $\mathrm{pH} 10.5$ (transition from doublet to singlet) indicates that the coalescence point is close to this $\mathrm{pH}$ value. This is supported by the fact that the exchange rates at this $\mathrm{pH}$, calculated according to eqs. 1 and 2, yield very similar values, i.e. $191 \mathrm{~s}^{-1}$ and $186 \mathrm{~s}^{-1}$, respectively.

\section{Possible mechanisms of exchange}

The values obtained for the exchange rate in Tris buffer are summarized in Table 1 and are plotted versus pH in Fig. 2. The semi-logarithmic representation (panel A) shows that the exchange rate first decreases with increasing $\mathrm{pH}$, it reaches a minimum around $\mathrm{pH}$ 9.5, this being followed by a steeper increase. The double-logarithmic representation (panel B) shows that the two segments have different profiles at low and high $\mathrm{pH}$ : The curve in this panel was generated based on the rules of Dixon [23] for the $\mathrm{pH}$ dependence of kinetic parameters of a species that is present in a $\mathrm{pH}$ dependent equilibrium linked by specific 
Table I: Line widths of the ${ }^{15} \mathrm{~N}$ resonance signal of the reduced $\mathrm{FMN} \mathrm{N}(5)$ atom as function of $\mathrm{pH}$ and estimation of the $\mathrm{N}(5)-\mathrm{H} \mathrm{pK} \mathrm{a}_{\text {. }}$

\begin{tabular}{cccc}
\hline $\mathrm{pH}$ & Line width $\left(\Delta \mathrm{v}_{\mathrm{I} / 2}-\Delta \mathrm{v}_{\mathrm{I} / 2}{ }^{\circ}\right)(\mathrm{Hz})$ & Exchange rate of $\mathrm{N}(5)-\mathrm{H}(\mathrm{s}-\mathrm{I})$ & $\mathrm{PK}_{\mathrm{a}}(\mathrm{calculated})$ \\
6 & 21 & 525 & 270 \\
6.7 & 42 & 242 & 107 \\
7.15 & 47 & 57 & 19 \\
7.8 & 34 & 9 & 20.5 \\
8.95 & 18 & 44 & 20.3 \\
9.05 & 6 & 191 & 20.0 \\
10.7 & 3 & 339 & 20.2
\end{tabular}

The flavin was $5 \mathrm{mM}$ in $250 \mathrm{mM}$ Tris $+100 \mathrm{mM} \mathrm{NaCl}$. The estimation of the $\mathrm{pK}_{\mathrm{a}}$ value is based on the line width of the corresponding ${ }^{15} \mathrm{~N}$ signal as described in the text.

pK's and includes reactions with linear dependences from either $\mathrm{H}^{+}$or $\mathrm{OH}^{-}$, or no dependence. For the "Dixon analysis" several modi of exchange can be envisaged, 4 of which $(2 \mathrm{~b}, 3 \mathrm{a}, 3 \mathrm{~b}$, and $3 \mathrm{c}$, ) are relevant for the $\mathrm{pH}$ range investigated in this study (Fig. 3). These include the reduced flavin at its 4 possible ionisation states along with the structures involved. In the present case the species undergoing ionisation is reduced flavin with $\mathrm{a} \mathrm{pK}_{\mathrm{a}} \approx 7$ for the $\mathrm{N}(1)-\mathrm{H}$ group [15]. At very low pH (Fig. 3, 1) the reduced flavin will be protonated at $\mathrm{N}(5)(\mathrm{pK} \approx-1.2,[24])$ and exchange will be with $\mathrm{H}_{2} \mathrm{O}$. This process (Fig. 3,1 ) is not expected to play a role in the present case. Similarly, the $\left[\mathrm{H}_{3} \mathrm{O}^{+}\right]$dependent mechanism (2a) is probably not

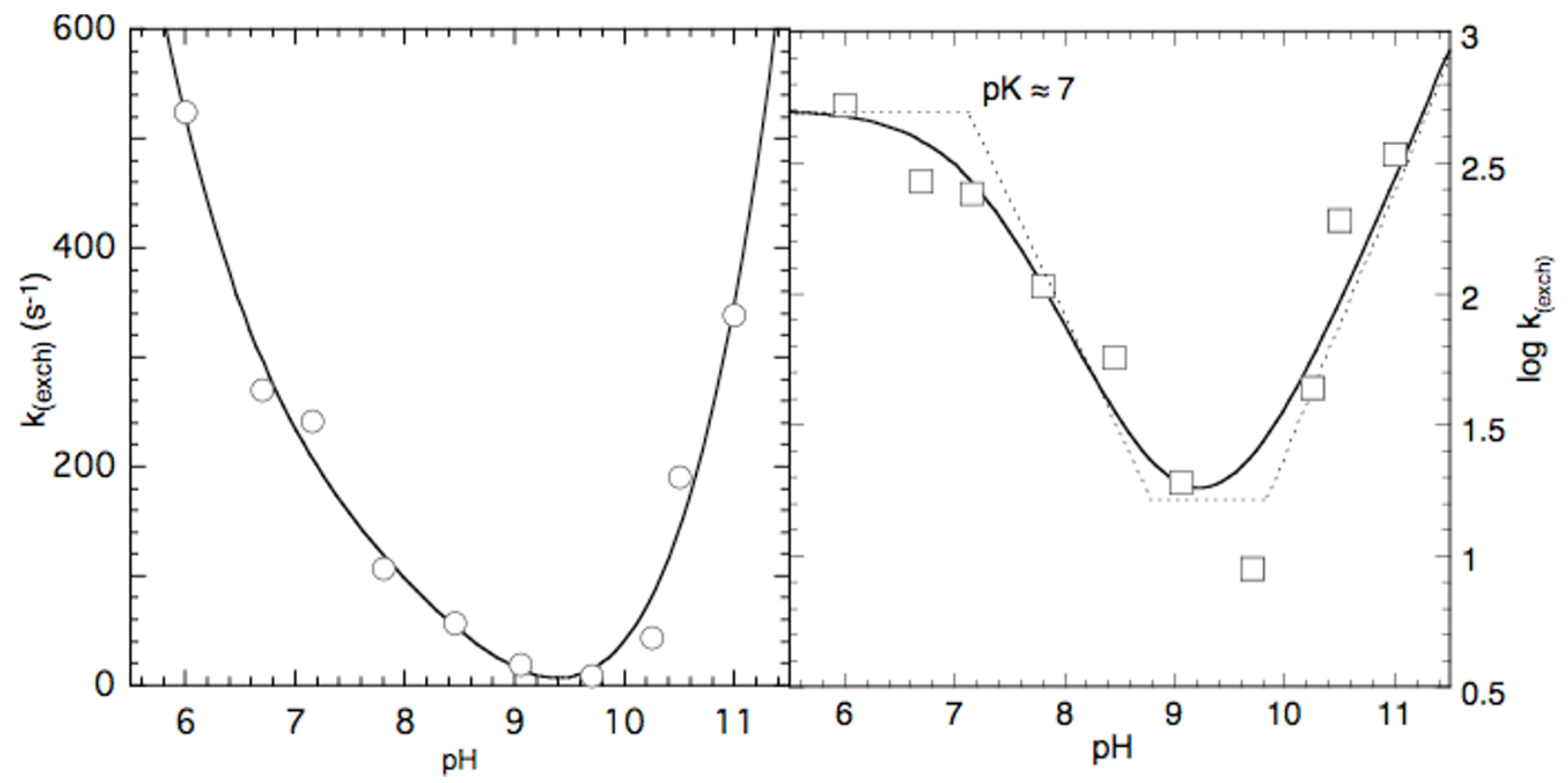

Figure 2

pH dependence of the rate of $\mathbf{N}(5)-\mathbf{H}$ exchange. Conditions as detailed in the Legend of Fig. I and in the Experimental section. Panel (A): Semi logarithmic plot. The line through the data points was generated with a polynomial algorithm and has no specific meaning. Panel (B): Same data as in panel (A), however logarithmic representation of the exchange rate. The curve (-) through the data points was generated according to Dixon's criteria and using a $\mathrm{pH}$ independent rate $=10^{2.7}\left(\mathrm{~s}^{-1}\right)$, the $\mathrm{pK}_{\mathrm{a}}$ $=7.15$ of reduced flavin (ionisation at $\mathrm{N}(\mathrm{I})-\mathrm{H}$ ), and apparent $\mathrm{pK}$ 's $=8.7$ and 9.8. The dashed lines (---) represent the single, unperturbed reactions that correspond to the processes described by equations $2-4$ in Fig. 3. Their "breaks" occur at changes in ionisation state $\left(\mathrm{pK}_{\mathrm{a}}\right)$ or reflect changes in mechanism. See text for further details. 


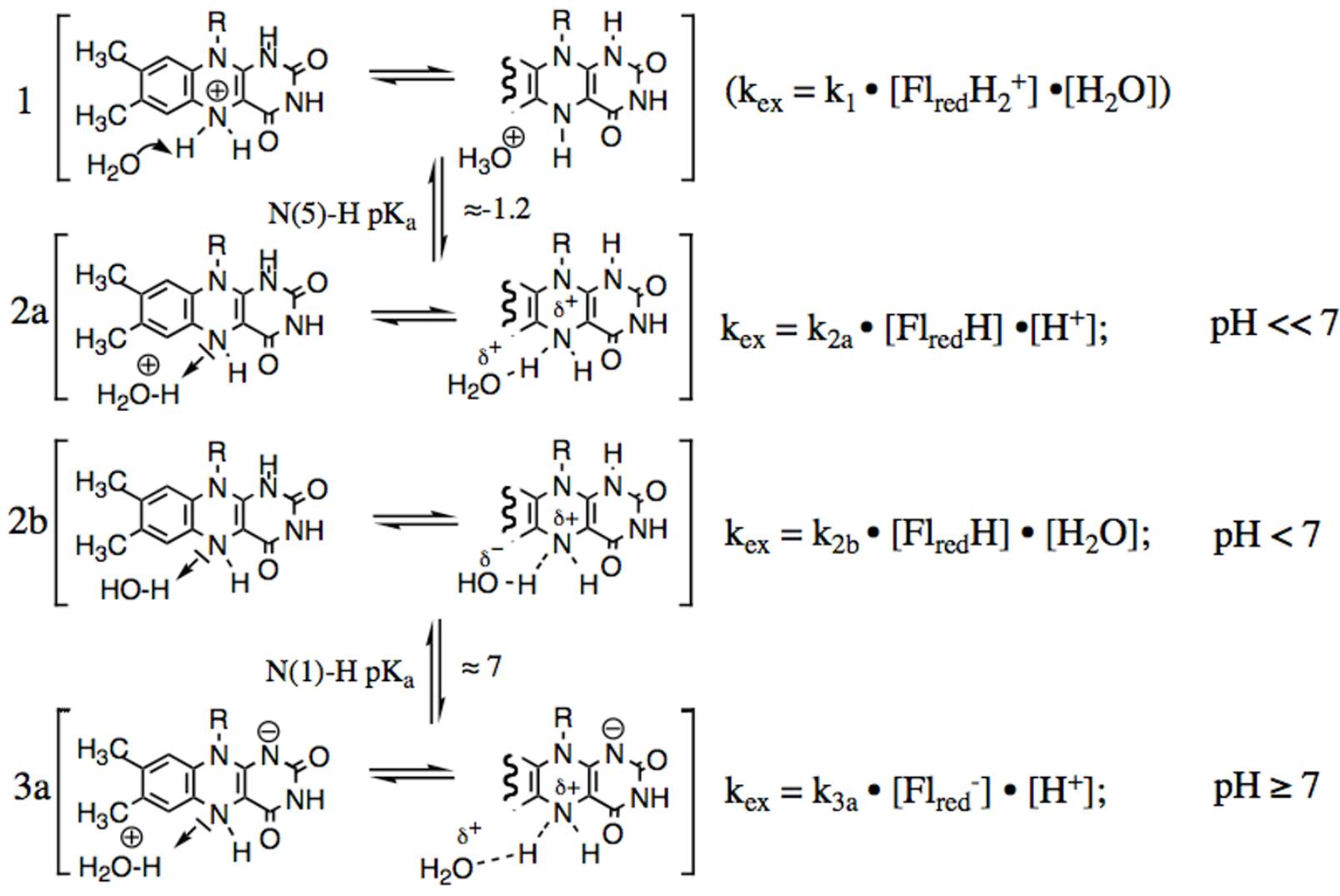

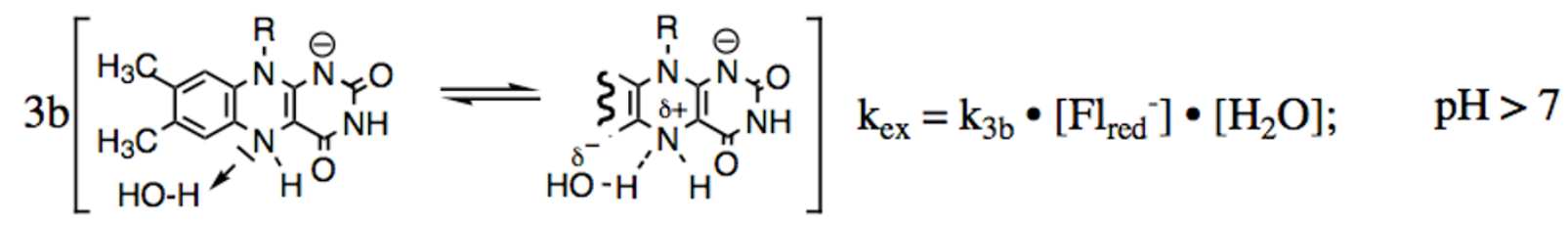

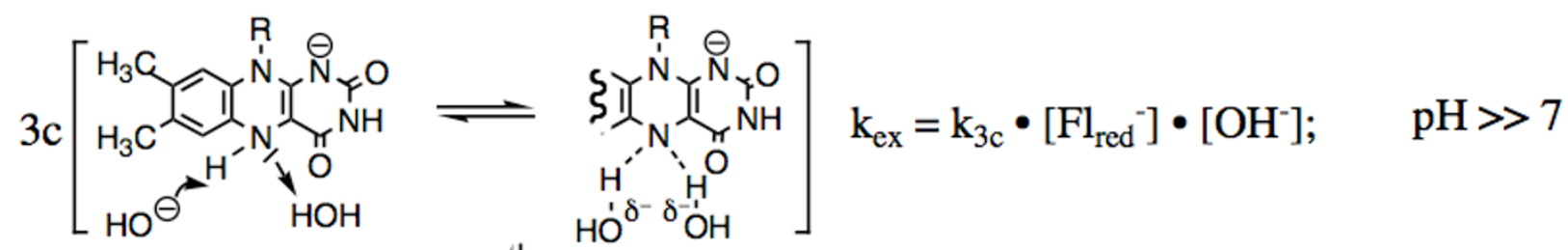
$\mathrm{N}(5)-\mathrm{H} \mathrm{pK}_{\mathrm{a}}>20 \| \quad\left(\mathrm{N}(3)-\mathrm{H} \mathrm{pK}_{\mathrm{a}} \approx 14\right)$

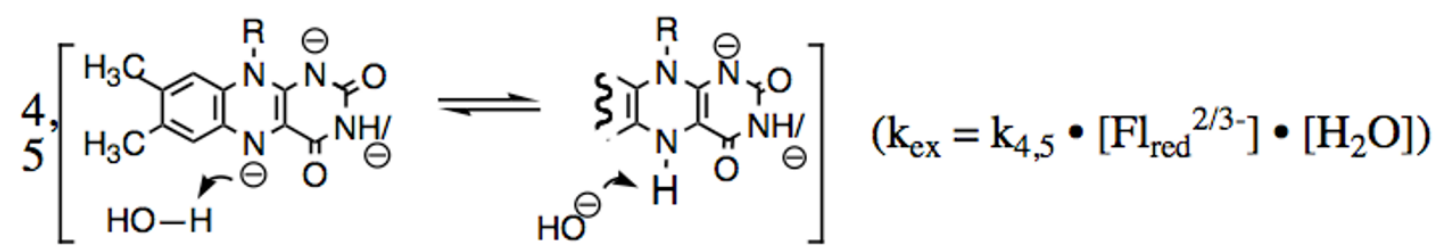

Figure 3

Species involved in $\mathrm{H}$-exchange at the reduced flavin position $\mathbf{N}(5)$ at its various stages of ionisation. (I) represents the exchange of cationic $\mathrm{N}(5)$. Species (2) involves exchange of neutral reduced flavin with $\mathrm{H}^{+}$or $\mathrm{H}_{2} \mathrm{O}$. (3) represent the modi of exchange of (mono-) anionic reduced flavin with $\mathrm{H}^{+}, \mathrm{H}_{2} \mathrm{O}$ or $\mathrm{HO}$. (4) and (5) are di- and tri-anionic reduced flavins that are likely to exchange with $\mathrm{H}_{2} \mathrm{O}$. 


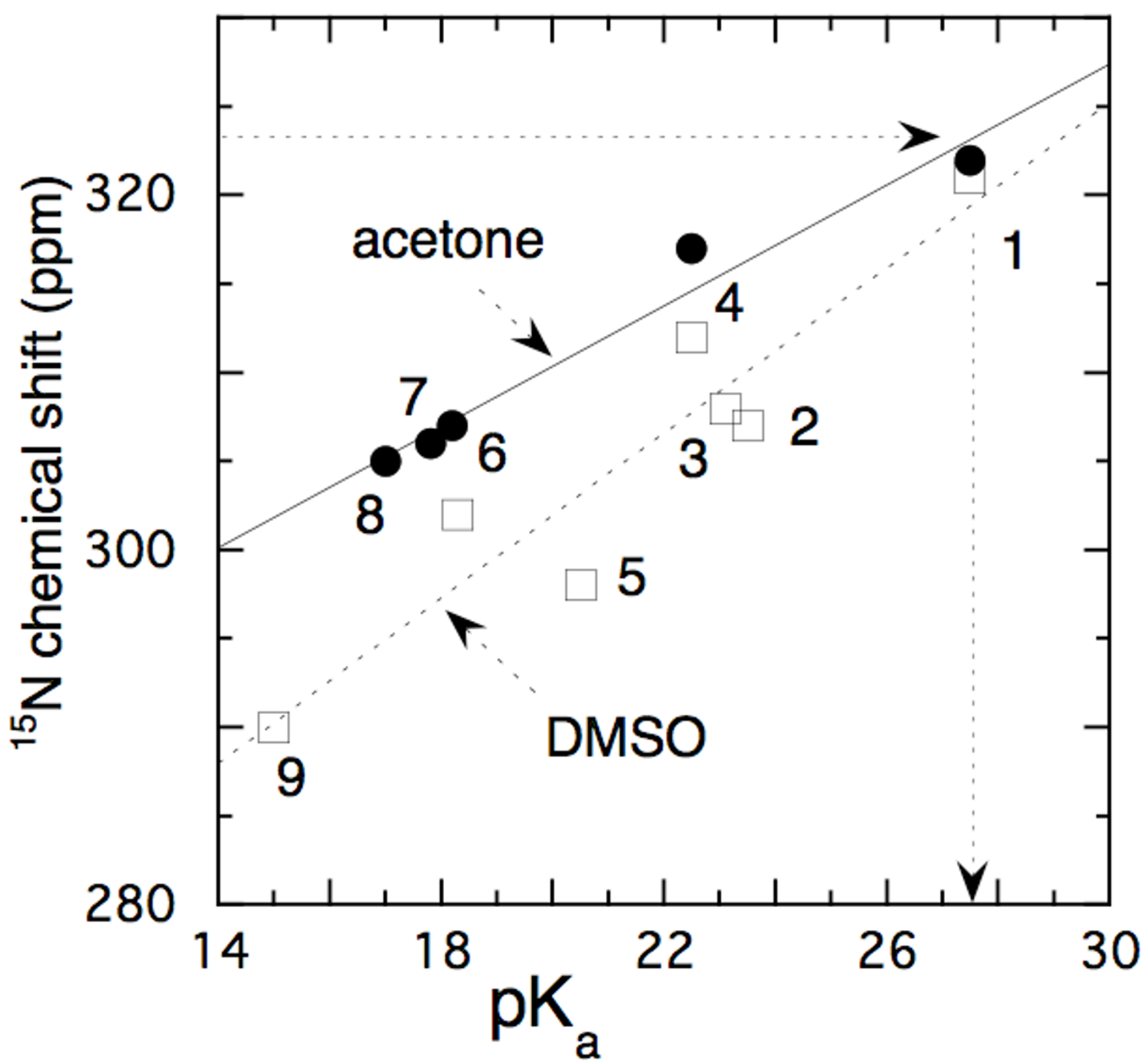

Figure 4

Correlation of ${ }^{15} \mathrm{~N}$-chemical shifts of aniline derivatives with their $\mathrm{pK}$ 's and extrapolation of the $\mathrm{pK}_{\mathrm{a}}$ value for $\mathbf{N}(5) H$ of reduced $\mathbf{F M N}$ based on its ${ }^{15} \mathbf{N}$ chemical shift. The compounds are: (I) aniline, 2: 2-azaaniline; (3) 4cyanoaniline; (4) 4-azaaniline; (5) 2,5-diazaaniline; (6) 4-nitroaniline; (7) 2-nitroaniline; (8) 4-chloro-2-nitroaniline; (9) 2,3-dinitroaniline (data from [34]). The horizontal arrow indicates the experimentally determined ${ }^{15} \mathrm{~N}$ chemical shift of $\mathrm{N}(5) \mathrm{H}$ of reduced flavin and vertical arrow extrapolates to an estimated $\mathrm{pK}_{\mathrm{a}} 26-30$.

relevant since the data suggest that a corresponding slope is absent at $\mathrm{pH}<6$. The neutral reduced flavin can exchange by reaction (2b) with $\mathrm{H}_{2} \mathrm{O}$ (Fig. $2 \mathrm{~B}$, horizontal segment up to $\mathrm{pH} \approx 7)$. At $\mathrm{pH} 7-9$ the $\left[\mathrm{H}_{3} \mathrm{O}^{+}\right]$dependent process (3a) then appears to become prominent (linear segment with slope $=1$ ). The profile in Fig. 2B clearly indi- cates that at higher $\mathrm{pH}\left[\mathrm{OH}^{-}\right]$dependent processes become dominant. This change in mechanism would be initiated by the switch of mode (2b) to the $\mathrm{pH}$ independent mechanism (3b)(short horizontal section between $\mathrm{pH}$ 9-10, Fig. 2B). This phase is envisaged to be followed by the $\left[\mathrm{OH}^{-}\right]$dependent mode $(3 \mathrm{c}$ ) (section at $\mathrm{pH}>10$, linear increase with $\left.\left[\mathrm{OH}^{-}\right]\right)$. In Fig. 3, the equilibrium between 


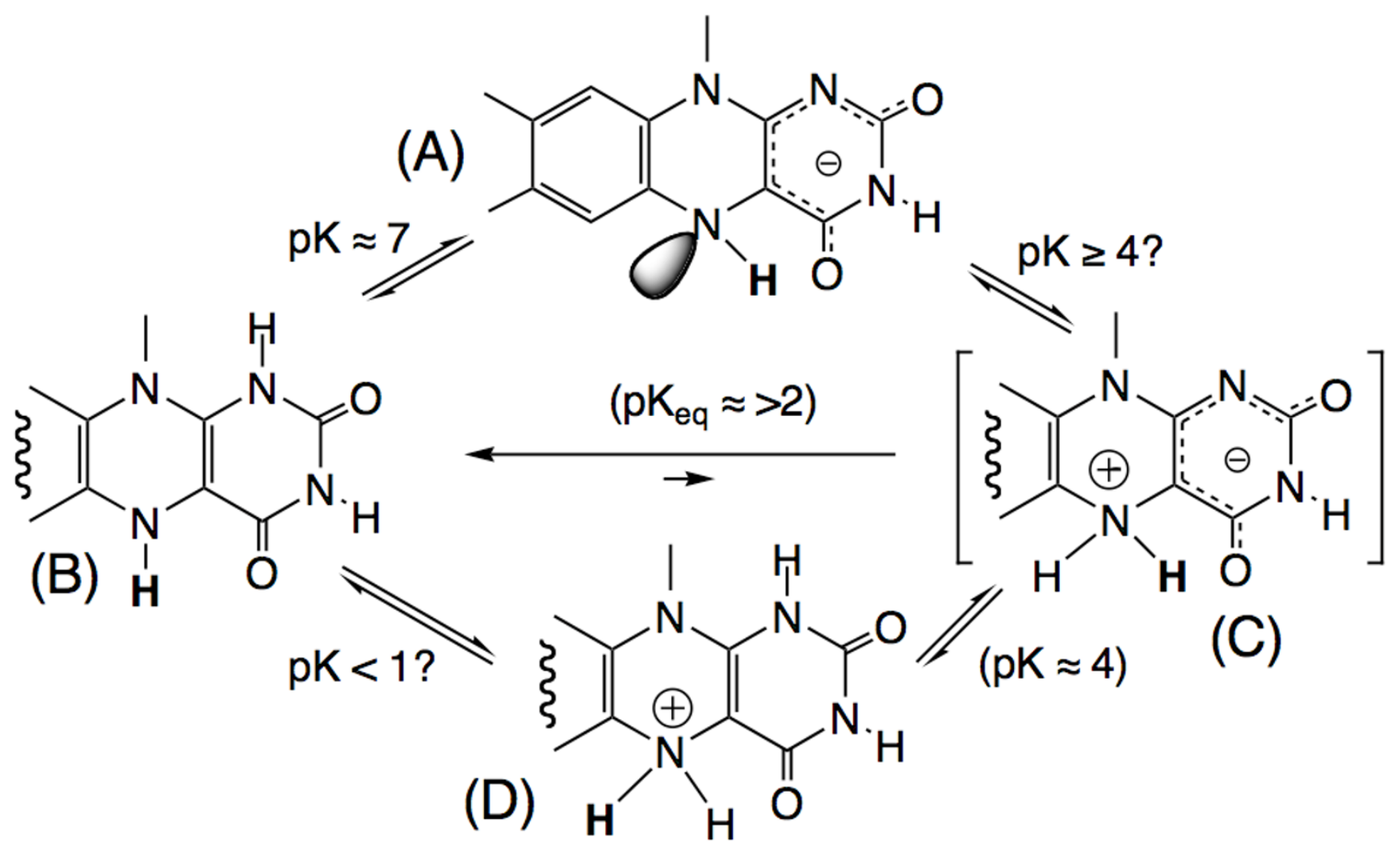

Figure 5

Selected ionisations and tautomeric forms of reduced flavin. $(A)$ and $(B)$ are the anionic, respectively the neutral forms of reduced flavin encountered at the active center of flavoproteins. The $\mathrm{pK}$ interconnecting $(A)$ and $(B)$ is $\approx 7$ in the free state [26], but can vary strongly at the active center of proteins. Protonation of $(A)$ at $N(5)$ to yield $(C)$ can not be observed in the free state but this chromophore is obtained by twofold alkylation at $N(5)$ [26]. The pK's linking species (B), (C) and (D) have been estimated from the properties of appropriate model compounds [26]. See text for further details.

species (2) $\Leftrightarrow$ (3) that encompasses the structures included by the square brackets, reflects the $\mathrm{pH}$ dependent change in ionisation state of the reduced flavin with a $\mathrm{pK}_{\mathrm{a}} \approx 7$. The point should be stressed that in the representation of Fig. $2 \mathrm{~B}$ and according to the Dixon's rules only the "break" at $\approx \mathrm{pH} 7$ can be attributed to a microscopic $\mathrm{pK}$. That corresponding to $\mathrm{pH} \approx 8.7$ is taken to reflect the change in mechanisms as outlined above, i.e. it is an apparent $\mathrm{pK}$ and has no structural significance since it cannot be attributed to ionisations of the exchange partners or of the buffer. The same probably holds true also for the break corresponding to a $\mathrm{pH} \approx 10$ since the $\mathrm{pK}_{\mathrm{a}}$ for the second ionisation of reduced flavin $(\mathrm{N}(3)-\mathrm{H})$ is estimated as $\approx 14$.

\section{Estimation of ionisation constants for the reduced flavin N(5)}

The $\mathrm{pK}_{\mathrm{a}}$ of the flavin N(5)-H corresponding to the following exchange process:

$$
\gamma_{\mathrm{N}(5)-\mathrm{H}}+\mathrm{HO}^{\Theta} \frac{\mathrm{k}_{1}}{\mathrm{k}_{1}} \succ_{\mathrm{N}(5)^{\Theta}}{ }^{\Theta}+\mathrm{H}_{2} \mathrm{O}
$$

can be estimated based on the general rates of proton transfer ( $k_{1}$ and $k_{-1}$, as indicated in equation 3 ) between two exchanging species connected to the equilibrium constants $\mathrm{K}_{\text {flavin-N(5) }}$ and $\mathrm{K}_{\mathrm{H} 2 \mathrm{O}}$ as in equation 4:

$\mathrm{K}_{\text {flavin- } \mathrm{N}(5)}=\frac{\mathrm{k}_{1}}{\mathrm{k}_{-1}} \cdot \mathrm{K}_{\mathrm{H} 2 \mathrm{O}}$

The exchange rate in the thermodynamically favorable direction can reasonably be assumed as being diffusion controlled (in this case $\mathrm{k}_{-1}=10^{10} \mathrm{M}^{-1} \cdot \mathrm{s}^{-1}$ ). For an estimation the HO-catalyzed process was selected since it is assumed to involve direct interaction with $\mathrm{HO}^{-}$(3c, in Fig. 3 ) and appears to best approximate a linear dependence from $\mathrm{pH}$. Thus the data between $\mathrm{pH} 9.7$ and 11 were employed. The values summarized in Table 1 were obtained using the mentioned value for a diffusion con- 
trolled proton transfer rate and the equilibrium constant of water $\left(=10^{-15.74}[25]\right)$. The average $\mathrm{pK}_{\mathrm{a}}$ value obtained from Table 1 is $20.2( \pm 0.3)$.

An estimation of the $\mathrm{pK}_{\mathrm{a}}$ of the flavin $\mathrm{N}(5)-\mathrm{H}$ can also be derived from the chemical shift of the ${ }^{15} \mathrm{~N}(5)$ center. ${ }^{1} \mathrm{~J}^{15}$ $\mathrm{N}-\mathrm{H}$ coupling constants are mainly governed by the hybridization of the nitrogen atom. Since the N(5)-H coupling constant is similar to that reported for eneamines and aniline derivatives [22] it is reasonable to assume that the $\mathrm{N}(5)$ hybridization is similar also to that of a series of substituted anilines that are used in the correlation diagram of Fig. 4, where their chemical shift is plotted against their reported $\mathrm{pK}_{\mathrm{a}}$ values. From the chemical shift for the reduced flavin $\mathrm{N}(5)$ of $\approx 60 \mathrm{ppm}$ [15] a $\mathrm{pK}>25$ is obtained. While this value is higher than that derived from the exchange experiments it correlates with the chemical entity of a phenylene diamine substituted with a moderately electron-deficient (neutral) pyrimidine moiety. Inspection of the chemical structures in the lowest row in Fig. 3 shows that in a chemical system the species that deprotonates at position $\mathrm{N}(5)-\mathrm{H}$ is a phenylene diamine linked to a pyrimidine carrying (already) two negative charges. The latter would undoubtedly increase the $\mathrm{pK}_{\mathrm{a}}$ for formation of the $\mathrm{N}(5)$ anion compared to a species in which neutral reduced flavin would ionize at position $\mathrm{N}(5)-\mathrm{H}$. The latter might be the case in a protein environment where specific charges or H-bridges might affect microscopic $\mathrm{pK}$ 's. Nevertheless protein induced $\mathrm{pK}$ shifts with values $>10$ units are unlikely within the same molecule since it would require a stabilisation energy $>59$ $\mathrm{KJ} / \mathrm{Mol}$. A pK $\mathrm{a}_{\mathrm{a}}$ value of $\geq 20$ is also in good agreement with the estimation by Venkataram \& Bruice $\left(\mathrm{pK}_{\mathrm{a}}=19-23\right.$ [3]) deduced from the $\mathrm{pH}$ dependence of the rates of decay of reduced flavin model compounds that have the 4a,5-dihydro structure.

The second ionisation of the reduced flavin relevant in an enzymological context is the (de)protonation at position $\mathrm{N}(1)$ with a $\mathrm{pK} \approx 7$ (species (A) $\Leftrightarrow(\mathrm{B})$, in Fig. 5). However, the locus of catalytic action is not N(1), but N(5). Thus, while the ionisation at $\mathrm{N}(1)$ plays a very important role in modulating the properties of reduced flavin and the flavin redox potential, it is unlikely to participate directly in base catalysis. A third ionisation that most likely is relevant in the biochemical context is the protonation of anionic reduced flavin (species (A) in Fig. 5) at position N(5)-H to yield the zwitterionic species (C). This species is not observed in free solution since the tautomeric equilibrium between species (B) and (C) favor the former by $\geq 2$ orders of magnitude [26]. The N(5)-dialkylated analog to species (C), however, has been described [26] and is converted to (D) with a $\mathrm{pK} \approx 4$. The combination of the equilibria shown in Fig. 5 thus allow the estimation of the equilibrium between species (A) and (C) (Fig. 5) to correspond to a putative $\mathrm{pK}>4$. While this "pK" has no direct significance in the free system it is easily conceivable that the protein could stabilize a negative charge at position $\mathrm{N}(1)$ as is probably the case with flavodoxins $[15,27,28]$, thereby facilitating formation of a putative species (C). In this context it should be noted that the most nucleophilic functional group in (A) is not $\mathrm{N}(1)-\mathrm{C}(2)=\mathrm{O}$, the locus of the negative charge, but $N(5)$ as reflected by the main position of alkylation [26].

\section{Conclusion}

Although a doublet for N(5)H of reduced free flavin can only be observed in the narrow $\mathrm{pH}$ range $8.5-10.5$, it has been documented for reduced flavoproteins at $\mathrm{pH}$ values as low as $5[15,27,28]$. This suggests that in specific, reduced flavoproteins $\mathrm{N}(5)-\mathrm{H}$ exchange is slow and that access of bulk solvent to this position is hindered. Occurrence of a doublet was observed in reduced thioredoxin reductase in which the $\mathrm{N}(1)$ atom is protonated [29]. Conversely, in reduced flavodoxins and many other flavoproteins the flavin $\mathrm{N}(1)$ position is not accessible for protonation [30] the flavin existing in the anionic form as long as the protein does not unfold ( $\mathrm{pH}$-dependent process). It thus appears that the rate of exchange at N(5)-H is not dependent on the ionisation state at $\mathrm{N}(1)-\mathrm{H}$ but will be dictated by the environment and accessibility of solvent of the specific protein. However, no such conclusion can be drawn for the $\mathrm{pH}$ range 8.5 - 10.5 where the doublet of the $\mathrm{N}(5)-\mathrm{H}$ is an inherent property of the reduced flavin. Unlike the $\mathrm{N}(5) \mathrm{H}$ resonance in reduced free flavin the $\mathrm{N}(3) \mathrm{H}$ resonance shows a narrow singlet over the whole $\mathrm{pH}$ range studied, indicating that proton exchange is fast. Therefore, the appearance of a doublet for this resonance in flavoproteins is compatible with hindered accessibility of this position for bulk water as previously interpreted [6].

The estimation of the $\mathrm{pK}_{\mathrm{a}}$ value of $\geq 20$ for the $\mathrm{N}(5)$ group in reduced flavin might be an useful parameter for the formulation of mechanisms involving it. For instance Urban and Lederer $[4,5]$ have postulated a deprotonated N(5) with a $\mathrm{pK}_{\mathrm{a}}$ of about 15 or even as low as 7 [5] as a catalytically relevant species in flavocytochrome $b_{2}$. While our data cannot exclude such a $\mathrm{pK}_{\mathrm{a}^{\prime}}$ it imposes specific energetic restraints for its formulation. On the other hand the reduced flavin $\mathrm{N}(5)-\mathrm{H}$ with an estimated $\mathrm{pK}_{\mathrm{b}^{\prime}} \geq 4$ for the free molecule possesses sufficient basicity to act as a base according to mechanism 3b (Fig. 3). Clearly, this property can be modulated by the protein environment to suit specific purposes. The conclusion is thus that the reduced flavin N(5)-H has properties that qualify it as a base catalyst for biochemical reactions. This could be realized in sev- 
eral cases: The recent elucidation of the structure of chorismate synthase $[12,13]$ suggests that $\mathrm{N}(5)-\mathrm{H}$ of the reduced flavin cofactor is involved in the abstraction of the hydrogen in the $C(6)$ pro- $R$ position of the substrate 5enolpyruvylshikimate 3-phosphate. A similar mechanism, abstraction of a proton from the $\alpha-\mathrm{CH}_{2}$ (pro-R) of an amine by monoamine oxidase [14], seems to be emerging, replacing the previously proposed single electron transfer mechanism. Likewise, $\mathrm{N}(5)$ appears to be involved in the elimination of halide from $\beta$-Cl-alanine catalyzed by D-amino acid oxidase [9]. At the active sites of these enzymes there is no amino acid functional group that could participate in the required base catalysis. The data presented in this paper thus sustain the notion that $\mathrm{N}(5)$ of the reduced flavin cofactor can play a direct role in the catalysis of some flavin-dependent enzymes, an involvement that has not yet been addressed in sufficient detail. Our studies towards a characterization of the hydrogen exchange processes at this position therefore lay the foundation for a critical assessment of this role.

\section{Methods}

\section{Experimental details}

The synthesis and purification of $\left[1,3,5,10-15 \quad \mathrm{~N}_{4}\right]-7$ methy1-10- ribitylisoalloxazine-5'-phosphate was described previously [31,32]. ${ }^{15} \mathrm{~N}-\mathrm{NMR}$ measurements were performed at $15^{\circ} \mathrm{C}$, if not otherwise stated, with a Bruker AM 500 NMR instrument equipped with an Aspect 3000 and a temperature control unit. NMR-spectra were recorded with $12 \mu$ s pulses $\left(=30^{\circ}\right.$ flip angle) and a relaxation delay of $2 \mathrm{sec}$. In a typical experiment $10 \mathrm{~mm}$ Wilmad precision NMR tubes contained $1.8 \mathrm{ml}$ of a 3 to 8 $\mathrm{mM}$ solution of flavin (or otherwise indicated in the text) in $250 \mathrm{mM}$ Tris/ $100 \mathrm{mM} \mathrm{NaCl}$-buffer and $0.2 \mathrm{ml} \mathrm{D}_{2} \mathrm{O}$ for field frequency lock. Reduction of the flavin solution was achieved by flushing the sealed NMR tube with argon before a two to three fold excess of a concentrated dithionite solution was added with a syringe. The $\mathrm{pH}$ of the resulting reduced solution was measured after the NMR experiment with a pH meter from Radiometer (Copenhagen, Sweden) equipped with a glass electrode from Ingold (Frankfurt, Germany). All ${ }^{15} \mathrm{~N}$ chemical shifts are expressed relative to liquid ammonia at $25^{\circ} \mathrm{C}$ and are corrected for bulk volume susceptibility. Neat $\mathrm{CH}_{3}{ }^{15} \mathrm{NO}_{3}$ $\left({ }^{\mathrm{TM}}\left(\mathrm{CH}_{3} \mathrm{NO}_{3}\right){ }^{-\mathrm{TM}}\left(\mathrm{NH}_{3}\right)=381.9 \mathrm{ppm}\right)$ was used as an external standard according to Witanowski et al [33]. The proton exchange rate $\left(1 / \tau_{\mathrm{e}}\right)$ was calculated according to Gutowsky et al [34] in the case of a fast exchange reaction, and according to Grunwald et al [35] in the case of a slow exchange reaction.

\section{Authors' contributions}

PM carried out most NMR experimental work with CS and evaluated the NMR data, he participated in drafting the manuscript.
SG conceived the study, participated in its design and coordination, as well as in the evaluation of the kinetic data and drafting of the manuscript.

FM synthesized the labeled flavins used in the cooperative studies with the group of HR, and was involved in the drafting and finalization of the paper.

\section{References}

I. Ghisla S, Massey V: Mechanisms of Flavoprotein-catalyzed Reactions. Eur J Biochem 1989, 181:1-17.

2. Bornemann S: Flavoenzymes that catalyse reactions with no net redox change. Nat Prod Rep 2002, 19(6):76I-772.

3. Venkataram UV, Bruice TC: On the Mechanism of Flavin-Catalyzed Dehydrogenation a, $\beta$ to an Acyl Function. The Mechanism of I,5-Dihydroflavin Reduction of Maleimides. J Am Chem Soc 1984, 106:5703-5709.

4. Urban P, Lederer F: Intermolecular hydrogen transfer catalyzed by a flavodehydrogenase, bakers' yeast flavocytochrome b2. J Biol Chem I985, 260(20): I I I I5-I I I 22.

5. Lederer F: Extreme pKa displacements at the active sites of FMN-dependent alpha-hydroxy acid-oxidizing enzymes. Protein Sci 1992, I(4):540-548.

6. Müller F: Nuclear magnetic resonance studies on flavoproteins. In Chemistry and Biochemistry of Flavoproteins Volume III. Edited by: Müller F. Boca Raton, Florida: CRC Press; 1992:558-595.

7. Umhau S, Pollegioni L, Molla G, Diederichs K, Welte W, Pilone MS, Ghisla S: The x-ray structure of $D$-amino acid oxidase at very high resolution identifies the chemical mechanism of flavindependent substrate dehydrogenation. Proc Natl Acad Sci USA 2000, 97(23): $12463-12468$.

8. Mattevi A, Vanoni MA, Curti B: Structure of D-amino acid oxidase: new insights from an old enzyme. Current Opinion in Structural Biology 1997, 7(6):804-810.

9. Molla G, Pilone MS, Pollegioni L, Ghisla S: Studies on the elimination reaction of Rhodotorula gracilis D-amino acid oxidase with $\beta$-chloro-D-alanine. In Flavins and Flavoproteins 2002: Proc 14th Int Symp, Cambridge, UK, 2002 Volume 2002. Edited by: Chapman S, Perham R, Scrutton N. Agency for Scientific Publ., Berlin; 2002:299-304.

10. Ghisla S, Pollegioni L: D-Amino Acid Oxidase: Still New Lessons from a Seventy Year Old Enzyme. Flavins and Flavoproteins, Proc 15th Int Symp 2005 in press.

II. Walsh CT, Krodel E, Massey V, Abeles RH: Studies on the elimination reaction of $D$-amino acid oxidase with $\alpha$-amino- $\beta$ chlorobutyrate. Further evidence for abstraction of substrate $\alpha$-hydrogen as a proton. I Biol Chem 1973, 248(6): 1946-1955.

12. Maclean J, Ali S: The structure of chorismate synthase reveals a novel flavin binding site fundamental to a unique chemical reaction. Structure (Camb) 2003, I I ( I 2): I499-I5II.

13. Lauhon CT, Bartlett PA: Substrate analogs as mechanistic probes for the bifunctional chorismate synthase from Neurospora crassa. Biochemistry 1994, 33(47): |4100-14108.

14. Edmondson DE, Mattevi A, Binda C, Li M, Hubalek F: Structure and mechanism of monoamine oxidase. Curr Med Chem 2004, I I(I5): 1983-1993.

15. Franken HD, Rüterjans H, Müller F: Nuclear-magnetic-resonance investigation of $15 \mathrm{~N}$ - labeled flavins, free and bound to Megasphaera elsdenii apoflavodoxin. Eur J Biochem 1984, 138(3):48I-489.

16. Moonen CT, Vervoort J, Müller F: Reinvestigation of the structure of oxidized and reduced flavin: carbon- 13 and nitrogen15 nuclear magnetic resonance study. Biochemistry 1984, 23(2I):4859-4867.

17. Rüterjans $H$, Kaun E, Hull WE, Limbach $\mathrm{HH}$ : Evidence for tautomerism in nucleic acid base pairs. I H NMR study of I5N labeled tRNA. Nucleic Acids Res 1982, 10(21):7027-7039.

18. Kaplan JI, Fraenkel G: NMR of chemically exchanging systems. New York: Academic press; 1980.

19. Martin G, Martin ML, Gouesnard JP: I5N-NMR Spectroscopy Volume 18. Edited by: Diel P, Fluck E, Korfeld R. Berlin: Springer Verlag; 1981:187-326. 
20. Binsch G, Lambert JB, Roberts BW, Roberts JD: Nitrogen-15 magnetic resonance spectroscopy II. Coupling constants. J Am Chem Soc 1964, 86:5564-5570.

21. Gunter H: NMR-Spectroscopy. Stuttgart: Thieme-Verlag; 1983.

22. Blomberg $\mathrm{F}$, Maurer $\mathrm{W}$, Rüterjans $\mathrm{H}$ : I5N nuclear magnetic resonance investigations on amino acids. Proc Natl Acad Sci USA 1976, 73(5):|409-|4|3.

23. Dixon M, Webb EC: Enzymes. New York: Longman/Academic Press; 1979.

24. Ghisla S, Macheroux P, Sanner C, Rüterjans H, Müller F: Ionization properties of reduced I,5-dihydroflavin, rates of $N(5)-H$ exchange with solvent. In Flavins and Flavoproteins Edited by: Curti B, Ronchi S, Zanetti G. Berlin, New York: Walter de Gruyter; 1991:27-32.

25. Adamson AW: A Textbook of Physical Chemistry. New York: Academic Press; 1973.

26. Ghisla S, Hartmann U, Hemmerich P, Müller F: Synthese, Struktur und Reaktivität von Dihydroflavinen. Liebig's Ann Chem 1973, 1973:1388-1415.

27. Yalloway GN, Mayhew SG, Boren SJ, Vervoort J: Effects of pH on the ${ }^{13} \mathrm{C}$ and ${ }^{15} \mathrm{~N}$ NMR spectra of the hydroquinone of Desulfovibrio vulgaris flavodoxin and its G6IA mutant. In Flavins and Flavoproteins Edited by: Ghisla S, Macheroux P, Sund H. Berlin: Agency for Scientific Publications; 1999: I87-190.

28. Vervoort J, Müller F, LeGall J, Bacher A, Sedlmaier H: Carbon-I3 and nitrogen-I5 nuclear-magnetic-resonance investigation on Desulfovibrio vulgaris flavodoxin. Eur J Biochem 1985, I 5 I ( I $): 49-57$

29. Eisenreich W, Kemter K, Bacher A, Mulrooney SB, Williams $\mathrm{CH}$ Jr, Müller F: I3C-, I5N- and 3 IP-NMR studies of oxidized and reduced low molecular mass thioredoxin reductase and some mutant proteins. Eur J Biochem 2004, 27 I(8): I437-I452

30. Ludwig ML, Schopfer LM, Metzger AL, Partridge KA, Massey V: Structure and oxidation-reduction behavior of I-deaza-FMN flavodoxins: modulation of redox potentials in flavodoxins. Biochemistry 1990, 29(45): 10364-10375.

31. van Schagen CG, Müller F: A I3C nuclear-magnetic-resonance study on free flavins and Megasphaera elsdenii and Azotobacter vinelandii flavodoxin. I3C-enriched flavins as probes for the study of flavoprotein active sites. Eur J Biochem I98I, I 20(1):33-39.

32. Müller F, Vervoort J, Lee J, Horowitz M, Carreira LA: Coherent anti-Stokes Raman spectra of isoalloxazines. J Ramn Spectrosc 1983, 14:106-117.

33. Witanowski M, Stefaniak L, Webb GA: Annu Rep NMR Spectros 198I, I I B: I- I 48.

34. Gutowsky HS, McCall DW, Slichter CP: Nuclear magnetic resonance multiplets in liquids. J Chem Phys 1953, 2 I (2):279-292

35. Grunwald E, Loewenstein A, Meiboom S: Rates and mechanisms of protolysis of methylammonium ion in aqueous solution studied by proton magnetic resonance. I Chem Phys 1957 27(3):630-640.
Publish with Biomed Central and every scientist can read your work free of charge

"BioMed Central will be the most significant development for disseminating the results of biomedical research in our lifetime. "

Sir Paul Nurse, Cancer Research UK

Your research papers will be:

- available free of charge to the entire biomedical community

- peer reviewed and published immediately upon acceptance

- cited in PubMed and archived on PubMed Central

- yours - you keep the copyright
BioMedcentral 